\title{
Nilai-nilai Agama Islam dalam Budaya dan Adat Masyarakat Aceh
}

\section{Cut Muthia*}

Prodi Komunikasi dan Penyiaran Islam, Fakultas Dakwah, Universitas Islam Bandung, Indonesia.

*cutmuthia411@gmail.com

\begin{abstract}
This study aims to find out how Islamic values are in the social, cultural situation of the people of North Kluet District, South Aceh Regency, Aceh Province. In North Kluet itself there are three ethnicities, three languages, who know each other. Not only that, there are also religious rituals and cultural rituals that are claimed to uphold Islamic values. The type of research conducted using ethnographic methods, with a descriptive qualitative approach that is descriptive analysis. Data was collected using the methods of observation, interviews, documentation, and literature. Overall, the results of this study give rise to theories, namely the existence of cultural integration, multicultural communication contained in social situations, as well as Islamic religious values in the North Kluet district community. The role of Islamic values in fact has an effect on the social situation of the people of North Kluet District, which is also very influential in every culture of the North Kluet community. These three aspects (social, cultural and Islamic) in the North Kluet region can be said to be Local Wisdom. So that Islamic values that exist in the community of North Kluet District, South Aceh Regency, are able to influence the culture and social of the local community, thus creating Islamic culture and customs.
\end{abstract}

Keywords: Islamic values, culture, multicultural communication, local wisdom, Kluet Utara district.

Abstrak. Penelitian ini bertujuan untuk mengetahui bagaimana nilai- nilai Islam dalam situasi sosial, kebudayaan masyarakat Kecamatan Kluet Utara Kabupaten Aceh Selatan Provinsi Aceh. Di Kluet Utara sendiri terdapat tiga etnis, tiga bahasa, yang saling berdampingan. Tidak hanya itu, terdapat juga ritual keagamaan serta ritual kebudayaan yang di klaim menjungjung tinggi nilai-nilai Islam. Adapun jenis penelitian yang dilakukan menggunakan metode etnografi , dengan pendekatan kualitatif deskriptif yang bersifat deskriptif analisis. Pengumpulan data dilakukan dengan menggunakan metode observasi, wawancara, dokumentasi, dan kepustakaan. Secara keseluruhan, hasil penelitian ini memunculkan implikasi teoritis, yaitu adanya keterpaduan budaya, komunikasi multikultural yang terdapat dalam situasi sosial, serta nilai-nilai agama Islam pada masyarakat kec.Kluet Utara. Peran nilai - nilai Islam nyatanya berpengaruh dalam situasi sosial masyarakat Kec.Kluet Utara juga sangat berpengaruh dalam setiap kebudayaan pada masyarakat Kluet Utara. Ketiga aspek (sosial,budaya dan Islam) di wilayah Kluet Utara ini dapat dikatakan sebagai Kearifan Lokal. Sehingga nilai - nilai Islam yang berada di masyarakat Kec.Kluet Utara Kab.Aceh Selatan, mampu mempengaruhi budaya serta sosial masyarakat setempat, sehingga menciptakan budaya dan adat Islami.

Kata Kunci: Nilai Islam, Kebudayaan, Komunikasi Multikultural , Kearifan Lokal, Kecamatan Kluet Utara. 


\section{A. Pendahuluan}

Di Aceh sendiri terdapat ungkapan Adat ngen hukom lagee zat ngen sifeuet (Adat dengan hukum bagaikan zat dan sifat), yang mana ungkapan dua penyatuan yang tak terpisahkan antara Ajaran Islam dengan budaya/ adat istiadat dalam keseharian masyarakat Aceh. Dalam kehidupan sehari-hari, orang Aceh selalu menggunakan ajaran Islam sebagai pedoman yang mesti ditaati, karena dengan ajaran Islam ini masyarakat Aceh dapat mensejahterakan hidupnya baik di dunia maupun di akhirat kelak.Sebagaimana kondisi Aceh yang sangat erat kaitannya dengan beberapa ritual budaya serta syariat islamnya, maka tak heran kota ini disebut sebagai salah satu daerah istimewa. Namun, tentu keistimewaan daerah Aceh ini, membuat Aceh memiliki ciri khas serta persepsi yang berbeda dengan daerah lain. Dimana nilai-nilai Islam diklaim sebagai budaya adat masyarakat Aceh itu sendiri. Sedangkan secara umum Islam adalah agama bersumber dari Allah Swt. dan budaya adalah karya manusia. Dengan demikian, agama bukan bagian dari budaya dan budaya bukan bagian dari agama. Lalu, bagaimana peran dakwah Islam melalui komunikasi antar budaya mampu mewarnai budaya serta kondisi sosial masyarakat Aceh, khususnya Kec.Kluet Kab.Aceh Selatan?.

Sehubungan masalah di atas, penulis tertarik untuk mengadakan penelitian secara ilmiah guna memperoleh gambaran mengenai nilai-nilai agama Islam pada budaya adat masyarakat Kecamatan Kluet Utara Kabupaten. Aceh Selatan Provinsi Aceh, serta upaya penyelesaiannya. Agar penelitian ini memperoleh target yang diharapkan maka dikemas dengan sebuah judul: "NILAI-NILAI AGAMA ISLAM DALAM BUDAYA ADAT MASYARAKAT ACEH (Studi Kasus Pada Masyarakat Kecamatan Kluet Utara Kabupaten Aceh Selatan)”.

Adapun Penelitian ini bertujuan untuk:

1. Memperoleh data terkait Situasi Sosial dan Budaya Masyarakat Kabupaten Aceh Selatan khususnya di Kecamatan Kluet Utara.

2. Mengetahui situasi budaya dan adat masyarakat Kecamatan Kluet Utara Kabupaten Aceh Selatan.

3. Memahami nilai-nilai Agama Islam dalam mewarnai budaya dan masyarakat Kecamatan Kluet Utara Kabupaten Aceh Selatan.

\section{B. Metodologi Penelitian}

Dalam penelitian ini, peneliti menggunakan metode Etnografi dengan pendekatan kualitatif deskriptif yang bersifat deskriptif analisis. Pengumpulan data dilakukan dengan menggunakan metode observasi, wawancara, dokumentasi, dan kepustakaan.

1. Nilai-nilai Agama Islam, Nilai-nilai keislaman merupakan bagian dari nilai material yang nampak dalam kenyataan pengalaman rohani dan jasmani. Nilai-nilai Islam merupakan tingkatan integritas kepribadian yang mencapai tingkat budi (insan kamil). Nilai- nilai Islam bersifat mutlak kebennarannya, universal dan suci.

2. Budaya, merupakan perkembangan majemuk budi daya, yang berarti daya dari budi. Pengertian ini menggambarkan bahwa budaya adalah prilaku yang dihasilkan oleh manusia secara sistematik melalui proses pemikiran dan pembelajaran dari lingkungan hidupnya. Secara harfiah atau literal budaya adalah peradaban, kemajuan berfikir dan akal budi, meliputi cara berpikir, bekelakuan dan cara manusia berhubungan dengan manusia lain

3. Adat, Menurut Koen Cakraningrat, Adat ialah suatu bentuk perwujudan dari kebudayaan, kemudian adat digambarkan sebagai tata kelakuan. Adat merupakan sebuah norma atau aturan yang tidak tertulis, akan tetapi keberadaannya sangat kuat dan mengikat sehingga siapa saja yang melanggarnya akan dikenakan sangsi yang cukup keras.

4. Situasi, adalah suatu keadaan sosial yang dilakukan oleh anggota masyarakat dalam lingkungannya. Adapun situasi dapat dikatan sebagai penafsiran seseorang yang terpengaruh norma sosial dan nilai sosial yang berlaku di dlam budaya masyarakat itu sendiri. 
5. Sosial, suatu tataan dari hubungan-hubungan sosial dalam masyarakat yang menmpatkan pihak tertentu (individu,keluarga,kelompok,kelas) didalam posisi-posisi sosial tertentu berdasarkan suatu sistem nilai dan norma yang berlaku pada suatu masyarakat di waktu tertentu.

6. Komunikasi Antar Budaya, menurut (Lustig dan Koster,1993) adalah suatu proses komunikasi simbolik, interpretatif,transaksional, dan kontekstual yang dilakukan oleh beberapa/sejumlah orang karena memiliki perbedaan derajat kepentingan, memberikan interpretasi dan harapan secara berbeda terhadap apa yang disampaikan dalam bentuk perilaku tertentu sebagai makna yang dipertukarkan.

7. Masyarakat merupakan sejumlah orang yang menempati suatu wilayah baik langsung maupun tidak langsung saling berhubungan sebagai usaha pemenuhan kebutuhan, terkait sebagai satuan sosial melalui perasaan solidaritas karena latar belakang sejarah, politik ataupun kebudayaan yang sama.

8. Kearifan Lokal (Local Wisdom), pada masyarakat masyarakat adat dibangun di atas prinsip-prinsip kearifan leluhur yang berarti perpaduan antara nilai-nilai budaya dan keislaman serta pengelolaan lingkungan yang tertanam pada tingkat kesadaran teologis..Masyarakat adat memposisikan diri sebagai khalifah (penguasa) di muka bumi yang mengatur dan mengelola sumber daya alam untuk membangun peradaban yang disebut.

\section{Pembahasan dan Diskusi}

Peneliti akan menyajikan data informan serta hasil terkait tiga permasalahan antara lain sebagai berikut:

Tabel 1. Data Informan

\begin{tabular}{|l|l|c|l|}
\hline No & \multicolumn{1}{|c|}{ Nama } & Usia & \multicolumn{1}{|c|}{ Profesi /Jabatan Sosial } \\
\hline 1. & Izwar., S.STP & 47 & Kepala Kec.Kluet Utara \\
\hline 2 & Santryanto & 23 & Mahasiswa \\
\hline 3 & Iskandar muda & 21 & Mahasiswa \\
\hline 4 & Ardiansyah & 25 & Mahasiswa \\
\hline 5 & Syukli yanjali & 20 & Mahasiswa \\
\hline 6 & Fahmil Alfian R & 21 & Mahasiswa \\
\hline 7 & Isra & 21 & Mahasiswa \\
\hline 8 & M.Kautsar & 21 & Mahasiswa \\
\hline 9 & M.Hasbar & 23 & Mahasiswa \\
\hline 10 & Rahman Mahil & 29 & Mahasiswa \\
\hline 11 & Tabrani & 32 & Guru \\
\hline 12 & M.Ridho Agung & 25 & Mahasiswa \\
\hline 13 & Dedek gunawan & 24 & Mahasiswa \\
\hline 14 & Dr.M.Yasar.,STP.,M.Sc. & 42 & Direktur Politeknik Aceh Selatan \\
\hline 15 & T. Masrizar & 47 & $\begin{array}{l}\text { Ketua Majelis Permusyawaratan } \\
\text { ulamakab.Aceh Selatan }\end{array}$ \\
\hline 16 & Adek Ulfa & 29 & Perawat \\
\hline
\end{tabular}




\begin{tabular}{|l|l|c|l|}
\hline 17 & Safril & 54 & Kepala Dinas Pariwisata Kab.Aceh Selatan \\
\hline 18 & Cut Aliya & 15 & Pelajar \\
\hline 19 & Khairul Habibi & 24 & Pegawai UDD PMI Banda Aceh \\
\hline 20 & Salmina & 21 & Pelajar \\
\hline 21 & Muzakir R.A & 31 & Ketua penggiat budaya dan tradisi Kluwat \\
\hline 22 & Zulfahmi & 31 & Mahasiswa \\
\hline 23 & Tgk. Lukman & 60 & Teungku Imeum Masjid \\
\hline 24 & Rizka Raudhatun S.Pd & 31 & Guru \\
\hline 25 & Munawir Sazali & 33 & Kadus \\
\hline 26 & M.Amir Afdi & 51 & Pegawai kantor kecamatan Kluet Utara \\
\hline 27 & Khairi Rahma S.pd & 32 & Guru \\
\hline 28 & Hasnida, S.Pd.i & 33 & Guru \\
\hline 29 & Fajarul Nasrijal S.Pd & 25 & Kepala dusun Taqwa gampong Simpang \\
\hline 30 & Al Mukrijal S.H.I & 27 & Penyuluh Agama Kec.Kluet Utara \\
\hline 31 & Teuku Syamsiar & 64 & Mantan Mukim Kuala Ba'u \\
\hline
\end{tabular}

Situasi Sosial Masyarakat Kec. Kluet Utara, Kab. Aceh Selatan. Prov. Aceh

1. Letak geografis.

Kluet raya merupakan bagian dari Kabupaten Aceh Selatan, dimana terdiri dari lima kecamatan yang dipisahkan oleh aliran sungai besar yang dikenal dengan Krueng Kluet dari hulu ke hilir. Kluet Utara dia tidak hanya berada di wilayah hilir melainkan terdapat sebagian yang masuk dalam wilayah hulu. Sehingga dapat dikatakan Kecamatan Kluet Utara ini terletak di bagian mulai dari hulu hingga hilir.

2. Interaksi Sosial Masyarakat Kec.Kluet Utara Kab.Aceh Selatan Prov.Aceh.

Adapun daerah Kluet diketahui sebagai kota yang heterogen. Hal tersebut didukung oleh terdapatnya tiga etnis atau suku. Masyarakat yang saling berdampingan antara 3 suku tersebut adalah: Kluet (etnis Aseli tanah Kluet), Aneuk Jame ( yang datang dari Sumatera Barat), dan Aceh (Etnis Asli Provinsi Aceh).

Sebagaimana data yang diperoleh bahwa, dari 5 kecamatan di Kluet raya bisa dikatakan Kecamatan Kluet Utara adalah satu-satunya wilayah yang ketiga etnis berkumpul secara merata.

Oleh sebab itu, Kluet Utara tergolong memiliki masyarakat dengan bermacam bahasa ibu, setidaknya ada bahasa Aceh, Aneuk Jamee, dan Kluet. Hal ini tidak terlepas dari asal-usul etnis masing-masing masyarakat. Berdasarkan salah satu infomarsi yang di peroleh, bahwa Kluet berdasarkan sejarahnya dahulu hanya dihuni oleh masyarakat etnis Kluwat/Kluet. Namun, karena salah satu alasan yaitu faktor geogafis, yang mana daerah Barat - Selatan provinsi Aceh ini pada masanya. menjadi jalur efektif perdagangan dll.

Selain dikenal akan kekayaan etnis yang dimilikinya, menurut beberapa informan berpendapat bahwa Kluet Utara juga dikenal sebagai daerah bersaudara berbudaya hal tersebut menunjukan bagaimana kekayaan masyarakat Kluet Utara dari segi bahasa dalam satu wilayah, yaitu bahasa Kluet, Aceh dan Aneuk Jame. Serta gaya tuturnya, yang jelas agak berbeda dengan masyarakat Aceh di kabupaten lainnya.

Kluet dikenal juga dengan karakter ramah serta solidaritas tanpa batas. masyarakat Kluet Utara ini memiliki ciri khas untuk menyapa terlebih dahulu baik itu kepada orang yang tidak 
dikenal terlebih kepada yang sudah dikenal. Budaya menyapa tersebut di klaim sebagai budaya asli orang yang ber-etnis Kluet. Namun, lamanya ketiga etnis di Kluet Utara hidup saling berdampingan, membuat budaya saling menyapa terlebih dahulu dapat dijumpai di seluruh wilayah Kluet Utara tanpa melihat etnis.

dengan kekayaan budaya mulai dari segi etnis hingga ragam bahasa dalam satu wilayah (bahasa Kluet, Aceh dan Aneuk Jame), Nyatanya tidak menghalangi masyarakat dalam bersosial, berinteraksi serta berkomunikasi satu sama lain. Situasi tersebut digambarkan dengan julukan sebagai daerah Bersaudara Berbudaya. Hal tersebut pun menunjukan bahwa masyarakat Kluet Utara adalah masyarakat berbudaya. Hal tersebut merujuk pada salah satu teori "Budaya dalah komunikasi, dan komunikasi adalah budaya".

Identitas sosial dengan sistem komunikasi multikultural, yaitu masyarakat yang begitu ramah, mempunyai ciri khas untuk menyapa terlebih dahulu baik itu kepada orang yang tidak dikenal (orang asing) terlebih kepada yang sudah dikenal, serta karakter solidaritas tanpa batas. Adapun, hal tersebut merujuk pada teori komunikasi multikultural yang dikemukakam oleh Sitaram, yaitu sebuah seni untuk memahami dan saling pengertian antara khalayak yang berbeda kebudayaan.

Masyarakat Kluet Utara dapat dikatakan juga sebagai sebagai masyarakat multikultur yang terdiri dari tiga etnis (Kluet, Aceh dan Aneuk Jame) beserta bahasa dan tuturnya, namun hidup saling berdampingan dan rukun satu sama lain. Hal tersebut, merujuk pada teori Alo liliweri, bahwa masyarakat multikultur adalah masyarakat yang struktur penduduknya terdiri dari beragam etnik dan keragaman itu menjadi sumber keragaman kebudayaan ataupun subkultur dari masing - masing etnik.

\section{Budaya Masyarakat Kec.Kluet Utara KAb.Aceh Selatan Prov.Aceh.}

Di Aceh pada umumnya,suatu tradisi dijungjung tinggi bahkan sulit dipisahkan antara tradisi dengan ajaran agama. Hal tersebut terungkap dalam hadi maja, "Hukom ngoen adat lagee zat ngon sipheut" (hukum dengan adat bagaikan zat dengan sifat), bahwa kedua hal tersebut tidak dapat dipisahkan dan menyatu dengan kehidupan masyarakat. Adat dan budaya yang berlaku dalam masyarakat Kluet Utara semua wajib bernafaskan Islam. Karena, hariko (hari ini) akan mewariskan adat dan budaya pada generasi selanjutnya,

Adat budaya yang berada di Kluet Utara ada yang berbaur dari ketiga etnis dan ada yang dilaksanakan sesuai dengan etnis masing - masing. Biasanya budaaya di Kluet Utara lebih didominasi oleh etnis Kluet, namun perbedaan yang terdapan di Kluet Utara tidak begitu banyak hanya beberapa saja .

Di Kluet Utara dapat dikatakan bahwa, semua aspek kehidupan masih menerapkan adat istiadat dan budaya. Di setiap pelaksanaan budaya tersebut tentu melibatkan setiap pemangku adat (keuchik) di setiap wilayah, dalam artian setiap pelaksanaan adat melibatkan berbagai unsur masyarakat. adapun beberapa kegiatan budaya dan adat di Kluet Utara sebagai berikut :

Kenduri Molod (kelahiran Nabi), kenduri jirat (kenduri kuburan), Kenduri Blang (kenduri setelah panen sawah), Meusilek petron, khanduri orang meninggal, khanduri tolak bala, mayar guru, makato, mesilek, tepung tawar/ peusijuek/pesunteng, turun tanah/turun bo lawe, adat meugang, Penerapan mahar,kenduri perkawinan,sapa linto/antar linto dan dara baro, Memasak putri mandi, senat rasul (khitan), samadiah (do'a bersama), Kanduri Laot, 4 Perkaro utang urang tuo (utang 4 perkara), Peh canang, Mandi Pucok, Rapa'I Geleng, Rapa'I debus, tari ranup lampuan dan lain sebagainya.

Salah satu penjelasan mengenai budaya terkait yang telah dipaparkan, sebagai berikut:

Pelaksanaan kenduri molod/maulid nabi yang dirayakan setiap tahunnya, yang mana disetiap gampong akan mengadakan acara berdzikir dan solawat bersama. Serta para ibu rumah tangga akan meyiapkan hidangan untuk jamuan, baik itu nasi, hingga buah-buahan. Menurut sejarahnya dahulu kerajaan Aceh merupakan salah satu wilayah dari kesulthanan Utsmani. Dimana sekitar abad ke-15, Aceh melawan Portugis dan meminta bantuan kepada khalifah Turki untuk melawan Portugis.

Singkat cerita, Ceh meraih kemenangan, dan ketika At-Tohir menanyakan imbalan apa yang pantas diberikan Aceh untuk segala bantuan yang telah diberikan oleh Utsmani tersebut, hal tak diduga sang Sulthan Utsmani hanya meminta masyarakat Aceh membuat perayaan 
Maulid selama Seratus hari. Hal tersebut khalifah memberi alasan karena, sejatinya kemenangan yang di peroleh tidak serta merta melainkan karena pertolongan Allah dan banyaknya Sholawat kepada Nabi Muhammad SAW. sebagai salah satu kekuatan terbesar atas kemenangan Aceh.

Maka Abdurrahman At-Tohir pun menyampaikan permintaan Sultan Utsmani kepada sultan Aceh, sehingga dikeluarkanlah Maklumat Kenuri untuk seluruh wilayah Aceh, yang berisikan tentang beberapa perayaan (Kenuri) seperti, Kenuri Maulid 100 hari, kenuri blang (Panen sawah), Kenuri Jerat dan kenuri lainnya yang hingga saat ini masih dapat dilihat

Secara keseluruhan, Budaya adat pada masyarakat Kluet memandang setiap prosesi yang dilakukan dalam ritual - ritual tersebut mempunyai suatu makna dan tujuan tersendiri dalam setiap hikmah tersendiri dalam setiap kehidupan masyarakat. Oleh sebab itu, menurut peneliti masyarakat Kluet Utara dapat dikatakan sebagai makhluk yang berbudaya, hal tersebut tergambar melalui beberapa kegiatan budaya seperti kesenian, keagamaan, hingga kehidupan sosial masyarakat setempat. Juga terdapatnya informasi bahwa, semua aspek kehidupan masyarakat Kluet Utara masih menerapkan adat istiadat dan budaya.

Makhluk yang berbudaya, peneliti merujuk pada salah satu teori yang mengartikan budaya sebagai the general body of arts, mencakup hasil karya , seni maupun pengetahuan filsafat atau bagian- bagian yang indah dari masyarakat, segala sesuatu yang diciptakan manusia baik yang konkrit maupun abstrak maka disebut budaya.karena kebudayaan adalah keseluruhan sistem gagasan tindakan dan hasil karya pemikiran manusia untuk memenuhi kehidupannya dengan cara belajar,dan semuanya tersusun dalam kehidupan masyarakat.

\section{Keberagamaan Masyarakat Kec.Kluet Utara Kab.Aceh Selatan, Prov.Aceh}

Adapun untuk mengetahui bagaimana keberagamaan pada masyarakat Kecamatan Kluet Utara Kabupaten Aceh selatan ini dapat diketahui berdasarkan :

1. Sejarah perkembangan Islam di wilayah Aceh khususnya Kecamatan Kluet Utara.

Di wilayah Kluet Utara, sebagaimana diketahui dahulunya adalah termasuk wilayah asli etnis Kluet, belum adanya etnis Aceh dan Jamee. Menurut beberapa informasi bahwa masyarakat tanah Kluet dahulu memeluk agama Hindu-Budha sebagai keyakinan nya, Hal tersebut adalah kondisi dimana Islam belum masuk ke wilayah nusantara, sehingga masyarakat setempat belum tersentuh oleh dakwah Islam.

Ketika Islam datang ke nusantara dan menjadi landasan kerajaan Aceh ,terdapat misi ekspansi wilayah serta dakwah Islam, dengan mengutus Teuku yang telah dibekali oleh kerajaan Aceh, ke setiap wilayah di Nusantara. Salah satunya adalah Teuku Marhum Kahar (Kesultanan Aceh ke-13), dalam perjalanannya dari Banda Aceh menuju Padang \, beliau melintasi jalur Barat-Selatan yang termasuk wilayah Kec.Kluet Utara. Pada masa tersebut Islam mulai berkembang di tanah Kluet. Seiring berjalannya waktu, nilai - nilai Islam pun disempurnakan oleh generasi setelah generasi Marhum Kahar hingga saat ini.

Pada masa kerajaan Aceh, terdapat suatu aturan yang dibuat yaitu, jika suatu wilayah sudah masuk dalam kekuasaan kerajaan Aceh maka masyarakat harus meyakini dan bertauhid kepada Allah SWT deengan memeluk Islam. Jika masyarakat tidak menerima dakwah Islam, maka bukan bagian dari kerajaan Aceh. Hal itu pula yang berlaku di tanah Kluet, sehingga pada saat itu masyarakat yang menolak dakwah Islam/ tidak beragama Islam memilih untuk berpindah tempat. Menurut cerita beberapa masyarakat bahwa Kluet yang non Islam tersebut berpindah ke daerah Sumatera Utara. Saat ini Islam telah menjadi bagian dari masyarakat Kluet Utara dari etnis apapun itu, dengan segala kelebihan dan kekurangannya. Salah satu contoh nya adalah masyarakat yang amat tunduk kepada ajaran Islam dan ta'at serta memerhatikan fatwa ulama, karena ulama lah yang menjadi ahli waris Nabi.

2. Pengaruh Nilai Islam dalam Budaya masyarakat Kecamatan Kluet Utara

Penghayatan terhadap ajaran Islam dalam jangka panjang itu, telah melahirkan budaya Aceh di Kecamatan Kluet Utara yang tercermin dalam kehidupan adat (kebiasaan sehari-hari). Adat itu lahir dari renungan para ulama,tokoh masyarakat, dikembangkan dan dilestarikan, dalam "Adat Bak Poe Teumeureuhom, Hukom Bak Syiah Kuala, Qanun Bak Putroe Phang, Reusam Bak Lakseumana." 
Adapun budaya/tradisi peniggalan hindu - budha masih terlihat coraknya dalam beberapa ritual kebudayaan, Islam sendiri datang untuk meluruskan/ membenarkan kepercayaan manusia, bukan mengubah segala cara hidup suatu kaum, nilai-nilai keislaman tersebut seperti:

1).Jalinan silaturahmi antar desa yang membuat persatuan dan kesatuan masyarakat di Kluet Utara sangatlah kuat. 2).Terujudnya keimanan yang kuat terhadap Tuhan yang maha Esa . 3).Pelaksanaan syariat Islam yang kaffah mengacu kepada qanun Aceh. 4).Makadari itu, setiap acara adat dan budaya selalu menyesuaikan dengan nilai-nilai Islami.

Adapun secara menyeluruh nilai - nilai Islam yang diperoleh antara lain : 1).Mempererat tali silaturahmi dengan diadakannya beberapa acara masyarakat, 2).Menjaga pakaian dengan menutup aurat, dan 3).Menjaga akhlak, sebagaimana yang tercermin dalam keramahan menerima tamu

Sebagaimana yang telah di peroleh, bahwasanya setiap adat serta budaya yang terdapat pada masyarakat Kluet Utara, peneliti mengemukakan bahwa adat tersebut merupakan adat Islam yang menjunjung tinggi nilai religiusitas ajaran islam, hal ini berdasarkan dengan kajian pustaka/ teori yang di peroleh bahwa dari Adat Aceh sendiri nyatanya bersumber pada empat rumusan klasifikasi adat, yaitu: 1). Adatullah, yaitu hukum adat yang bersumber hamper seluruhnya (muhlak) pada hukum Allah (Al-quran dan Hadist). 2) Adat Tunnah, yaitu adat istiadat sebagai manifestasi dari Qanun dan reusam yang mengatur kehidupan masyarakat. 3).Adat Muhakamah, yaitu hukum adat yang dimanifestasikan pada asas musyawarah dan mufakat. Dan 4).Adat Jahiliyyah, yaitu adat istiadat dan kebiasaan - kebiasaan masyarakat yang kadang-kadang tidak sesuai dengan ajaran Islam, namun masih ada yang digemari oleh masyarakat.

Hal ini peneliti menyatakan bahwa dalam proses internalisasi nilai-nilai Islam pada suatu masyarakat Kluet Utara, dibutuhkan peran seorang Da'i (mubaligh) seperti T.Marhum Kahar. Hal ini merujuk pada pengertian peran da'i itu sendiri, yang mana da'I adalah orang Islam yang secara syariat mendapat beban dakwah untuk mengajak kepada jalan agama Allah Swt.

Adapun hasil analisis hasil mengenai kebijakan kerajaan Aceh pada masa abad ke-14, politik sebagai media dakwah. Tentunya politik dengan penuh keyakinan serta komitmen kepada Allah Swt. Tujuan dari politik sebagai media dakwah ini bukanlah kekuasaan/atau tercapainya suatu kepentingan sendiri. Adapun kekuasaan,pengaruh,kepentingan,posisi politik,dll. tidak termasuk dalam tujuan, melainkan sebagai sarana untuk mencapai tujuan yang sesungguhnya, yaitu pengabdian kepada Allah semata.

Sebagaimana dalam Qs. Al-An'am: 162:

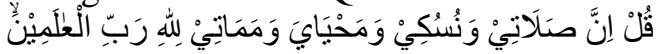

Yang berarti : Katakanlah (Muhammad), Sesungguhnya salatku, ibadahku, hidupku dan matiku hanyalah untuk Allah, Tuhan seluruh alam. (Qs. Al-An'am:162)

Berdasarkan peristiwa diatas, dapat dikatakan hal tersebut merupakan bagian dari dakwah lintas budaya, yang mana Islam dapat diterima oleh masyarakat yang memiliki kebiasaan -kebiasaan secara turun temurun. Sebagaimana pengertian dakwah lintas budaya itu sendiri, adalah sebuah proses dakwah dengan mempertimbangkan keragaman budaya antara da'i dan mad'u.

Secara keseluruhan mengenai keberagamaan masyarakat kluet dalam ketiga aspek (sosial,budaya dan Islam) dapat dikatakan sebagai Kearifan Lokal. Sebagaimana merujuk pada teori kearifan lokal masyarakat adat dibangun di atas prinsip-prinsip kearifan leluhur yang berarti perpaduan antara nilai-nilai budaya dan keislaman serta pengelolaan lingkungan yang tertanam pada tingkat kesadaran teologis. Masyarakat adat memposisikan diri sebagai khalifah (penguasa) di muka bumi yang mengatur dan mengelola sumber daya alam untuk membangun peradaban yang disebut. Iklan Le Minerale dalam penelitian ini meliputi attention (perhatian), interest (minat), desire (hasrat), decision (keputusan), dan action (tindakan). Sedangkan kesadaran merek meliputi bahwa brand unaware, brand recognition, brand recall, dan top of mind.

Hasil dari penelitian terlihat bahwa setelah responden menyaksikan iklan Le Minerale, semakin adanya kesadaran terhadap merek Le Minerale. Penelitian ini mendapatkan hasil bahwa terdapat hubungan antara iklan Le Minerale dengan kesadaran merek. Dari hasil wawancara dengan beberapa responden, iklan Le Minerale memiliki cukup daya tarik sehingga responden 
cepat mengingat produk air mineral ini. Proses mengingat hasil dari melihat iklan Le Minerale mendorong beberapa responden untuk mencoba bahkan membeli produk ini.

Konsumen akan lebih memilih suatu produk yang lebih dikenalnya atau diketahuinya, dibandingkan dengan membeli suatu produk yang belum pernah dikenalnya sama sekali. Untuk menimbulkan kesadaran merek pada konsumen dibutuhkan suatu stimulus atau hal-hal yang dapat merangsang munculnya kesadaran merek tersebut. Melalui iklan tersebut dan terciptanya pembeda tersebut dapat memunculkan untuk melakukan keputusan pembelian dikarenakan konsumen merasa tertarik dengan promosi yang dilakukan perusahaan.

\section{Kesimpulan}

Berdasarkan hasil penelitian bab 3 yang telah dilakukan, maka dapat disimpulkan dalam penelitian ini sebagaimana terkait tga permasalah pook yaitu, sebagai berikut :

Pertama, berkaitan dengan bagaimana situasi sosial masyarakat kec.Kluet Utara? Kecamatan Kluet Utara merupakan salah satu Kecamatan dari 18 kecamatan di Kabupaten Aceh Selatan, Provinsi Aceh. Kecamatan ini terdiri dari 3 mukim (kelurahan) dan 21 gampong (Kampung) . Situasi sosial masyarakat di Kec. Kluet Utara dikenal dengan karakter ramah, serta memiliki rasa gotong royong yang tinggi.

Di samping itu, Kluet Utara juga dikenal sebagai daerah Bersaudara Berbudaya hal tersebut menunjukan bagaimana kekayaan masyarakat Kluet Utara sebagai kota yang heterogen yang sebabkan oleh tiga etnis atau suku yang saling berdampingan dalam kecamatan tersebut. Adapun 3 etnis/suku terdiri dari, Kluet (mayoritas), Aneuk Jame, dan Aceh. Dari ketiga etnis tersebut memiliki bahasa yang berbeda-beda, namun mayoritas masyarakat Kluet mampu menguasai ketiga bahasa tersebut. Hal tersebut pun merujuk pada salah satu teori "Budaya dalah komunikasi, dan komunikasi adalah budaya". Masyarakat nya dapat disebut sebagai masyarakat multikultural, berdasarkan keberagaman etnis. Dan profesi baik petani, nelayan, pegawai negeri sipil, pekerja swasta, hingga pengangguran dapat ditemukan, Namun, Kehidupan sehari-hari masyarakat di Kluet profesinya lebih didominasi oleh petani.

Kedua, budaya tersebut tentu melibatkan setiap pemangku adat (keuchik) di setiap wilayah, dalam artian setiap pelaksanaan adat melibatkan berbagai unsur masyarakat, pemangku adat dan Ulama. Semua pelaksanaan ritual kebudayaan sudah mengalami pergeseran dan internalisaasi nilai-nilai Islam.

Ketiga, Berkaitan dengan Nilai-nilai Islam dalam Budaya adat masyarakat Kluet Utara, secara keseluruhan budaya dan adat didominasi oleh nilai-nilai agama Islam. Meskipun terdapat peninggalan tradisi Hindu-Budha, namun keseluruhan budaya adat dan tradisi masyarakat sudah syarat akan nilai-nilai Islam. Hal ini sejalan dengan masuknya Islam ke Nusantara yang mempengaruhi setiap tradisi, budaya serta sosial masyarakat Kecamatan Kluet Utara Kabupaten Aceh Selatan Provinsi Aceh. Sehingga Islam sendiri datang untuk meluruskan/ membenarkan kepercayaan manusia, bukan mengubah segala cara hidup suatu kaum, nilai-nilai keislaman tersebut seperti : 1). Jalinan silaturahmi antar desa yang membuat persatuan dan kesatuan masyarakat di Kluet Utara sangatlah kuat. 2).Terujudnya keimanan yang kuat terhadap Tuhan yang maha Esa. 3).Jalinan silaturahmi antar desa yang membuat persatuan dan kesatuan masyarakat di Kluet Utara sangatlah kuat. 4).Terujudnya keimanan yang kuat terhadap Tuhan yang maha Esa. Dan 4).Pelaksanaan syariat Islam yang kaffah mengacu kepada qanun Aceh.

Maka dari itu, setiap acara adat dan budaya selalu menyesuaikan dengan nilai - nilai Islami sederhananya seluruh masyarakat diwajibkan untuk menutup aurat jika keluar rumah. 


\section{Daftar Pustaka}

\section{Buku:}

[1] Alo liliweri, (2005) Prasangka dan konflik :komunikasi lintas budaya masyarakat multikultur.Yogyakarta: LKis Yogyakarta

[2] Alo Liliweri. (2009) Makna Budaya dalam Komuinikasi Antarbudaya.Yogyakarta: PT LKIS Printing Cemerlang.

[3] Aripuddin,Acep. (2012)., Dakwah Antar Budaya,Bandung,:remaja Rosdakarya.

[4] Dannerius Sinaga, (1988) Sosiologi dan antropologi. Jakarta:Intan Pariwara.

[5] Hoesin, Muhammad.(2018). Islam dan Adat Aceh. Banda Aceh: Majelis adat Aceh.

[6] Ismail,Badruzzaman,, (2018) Ensiklopedia Budaya Adat Aceh.Banda Aceh:MAA.

[7] Mulyana, Deddy,(2007) Ilmu Komunikasi: Suatu Pengantar. Bandung : Remaja Rosdakarya

[8] Rahman, M. T.(2011) Glosari Teori Sosial.Bandung,:Ibnu Sina Press.

[9] Salim, Peter dan Yenny Salim.(2002) Kamus Bahasa Indonesia Kontemporer. Jakarta: Modern English Press

[10] Spradley, James, (2006) Metode etnografi Yogyakarta:Tiara wacana.

[11] Wahidin, Saputra, M.A,(2011)Pengantar Ilmu Dakwah. Jakarta:Raja Grafindopersada.

[12] Jurnal/Skripsi:

[13] Effendi,dkk, kearifan local berdasarkan nilai - nilai agama sebuah kasus pada penduduk asli Indoneisa, ,no.3 Vol.18 tahun 2020, hlm.1402.

[14] Fhatarani,Batubara,Innaka, Perbedaan Komunikasi Antar Kebudayaan Yang Berbeda,dalam Jurnal Indonesian Institute for Counseling, Education and Therapy (IICET),2016, Vol. 4 No. 3, hlm.33

[15] Syamsul Hubungan politik dan dakwah,MediaTor, vol.6,no.1 tahun 2005. Hlm.11

\section{Internet:}

[1] https://id.wikipedia.org/wiki/Budaya\#: :text=Menurut\%20Edward\%20Burnett\%20Tylo r\%2C\%20kebudayaan,didapat\%20seseorang\%20sebagai\%20anggota\%20masyarakat.Di unduh17/03/21 pukul 16.48.

[2] M. Asrori Ardiansyah, M.Pd. 2014, Pengertian dan Konsep Nilai Dalam Islam, dalam http://kabar-pendidikan.blogspot.com/2011/04/pengertian-dan-konsep-nilai-dalamislam.html, diunduh 02/04/21 pukul 22.14.

[3] Muhammad Wiharto : https://lppi.unisayogya.ac.id/ diunduh 15/03/2021 pukul 14.23 